-Journal Publications . Research Consultancy

\title{
QUANTITATIVE EVALUATION OF SHRINKAGE POROSITY IN AISi9 CAST ALLOY AS FUNCTION OF TITANIUM ADDITION AND \\ CASTING PARAMETERS
}

\author{
B. AIT EL HAJ, A. BOUAYAD \& M. ALAMI \\ Department of Materials and Processes, National Graduate School of Arts and Crafts,
}

My Ismail University, Meknes, Morocco

\begin{abstract}
In the present research, effects of titanium addition as grain refiner combined with casting parameters on the porosity in the AlSi9 alloy was studied. Porosity was investigated via TATUR test. The casting parameters studied are: pouring temperature and initial mold temperature. The total porosity was experimentally quantified by densimetry method. A small decrease in porosity value was observed with increasing the pouring temperature from 700 to $800{ }^{\circ} \mathrm{C}$. It has been found that the effect of grain refinement by titanium addition on the porosity is more important, when the liquid metal was poured at $700^{\circ} \mathrm{C}$. Specimen poured in preheated mold at $300^{\circ} \mathrm{C}$ present small values of porosity.

KEYWORDS: Porosity, Aluminum-Silicon Alloy, TATUR Test, Grain Refinement \& Casting Parameters
\end{abstract}

Received: Aug 27, 2018; Accepted: Sep 17, 2018; Published: Nov 03, 2018; Paper Id.: IJMPERDDEC201841

\section{INTRODUCTION}

Porosity is a major defect, which can occur in cast parts after solidification and affects mechanical properties [1], in particular a reduction of strength, elastic limit, hardness, and resistance to fatigue. It is commonly accepted that the porosity in aluminum alloys is due to the existence and combination of two phenomena: hydrogen dissolution and metal shrinkage during solidification[1,2]. Gas porosity occurs due to the decrease in the solubility of hydrogen in aluminum during solidification while shrinkage porosity occurs during the solidification, and is the result of the difference in density between liquid and solid state. Inability of liquid metal to feed the inter dendritic regions gives rise to shrinkage[3, 4]. It may occur as micro shrinkage dispersed in the interdendritic regions.

The excellent foundry and mechanical properties of A1- Si alloys make them popular candidates for automotive applications. The use of aluminum and its alloys in industry has increased considerably in recent decades. Aluminum silicon alloys (Al-Si) offer excellent castability, good corrosion resistance and good physical and mechanical properties[5-8].

Considering the porosity formation based on the interdendritic feeding, the control of the formation of the eutectic and $\alpha$ - $\mathrm{Al}$ primary phases is of great importance on solidification mode. Casting quality is improved by reducing the size of $\alpha$ - $\mathrm{Al}$ grains and controlling its morphology through the refinement process. In general, there are three main methods of grain refinement in aluminum alloys: (i) Cooling rate control, (ii) grain refiner addition, (iii) Agitation of the metal during cooling[9]. 
In industry, the treatment of liquid metal plays a predominant role in the multiplication of nucleation sites, which considerably improve the characteristics of Al-Si alloys[10,11]. The grain refinement mechanism is based on the creation of heterogeneous germination sites that are dispersed in the liquid metal. The particles added in very small quantities act as preferential sites of germination for aluminum dendrites, and thus lead to the reduction in the size of the grains. It is necessary to create a large number of solidification sites which allow the refinement of the structure, and consequently the improvement of the mechanical characteristics. Titanium is known as a refiner of proeutectic phase of hypoeutectic Al-Si alloys [12]. The efficient concentration of this element in the alloy and its effect is therefore the object of this study.

The process parameters are crucial to obtain cast metal, without defect in die casting. The casting temperature and initial mold temperature affect the solidification by changing the cooling rate. Increasing the cooling rate reduces the solidification time and refines the grain size. The solidification time directly affects the ability of the liquid to feed the solidifying interdendritic region. Moreover, the grain size has a great influence on the pore size and their location around the grain.

In die casting, the initial mold temperature plays an important role in determining the microstructure of cast parts. In general, a high initial mold temperature has an effect on the microstructure, and thus on the porosity formation.

The TATUR test is sensitive to subtle changes in solidification mode and can be used to study the effect of solidification conditions and grain refiner addition[13]. In this study, this test was used to quantify the combined effect of pouring temperature, initial mold temperature and small amount of grain refiner (Titanium) addition on the porosity formation.

\section{MATERIAL SET METHODS}

\section{Studied Alloy}

In this study, we used the aluminum silicon alloy EN AC-44400 known by its excellent casting properties, good resistance to hot tearing and corrosion, good machinability and excellent weldability. The nominal chemical composition is shown in Table 1:

Table 1: Chemical Composition of the Cast Alloy EN AC-44400 (Wt.\%)

\begin{tabular}{|c|l|c|c|c|c|c|c|c|c|}
\hline Alloy & ISO Standardisation & Si & Mg & Fe & Cu & Zn & Mn & Ti & Al \\
\hline Standard EN AC-44400 & AlSi9 & $8-11$ & 0.1 & $0.65(0.55)$ & $0.1(0.08)$ & 0.15 & 0.5 & 0.15 & bal. \\
\hline
\end{tabular}

The alloy ingots were cut and melted in a graphite crucible using an electric resistance furnace. In order to study the effect of the casting temperature, four casting temperatures were chosen, namely $700,730,765$, and $800{ }^{\circ} \mathrm{C}$. The effect of initial mold temperature was studied and selected to be 150 and $300{ }^{\circ} \mathrm{C}$. Titanium is known to be a grain refiner of the proeutectic phase of hypoeutectic Al-Si alloys. In order to perform grain refinement and to study the effect of the concentration of this element in the AlSi9 alloy, titanium is supplied in the melt in the form of potassium fluotitanate $\left(\mathrm{K}_{2} \mathrm{TiF}_{6}\right)$ salt. The percentage of the titanium by weight of the melt of the metal was: $0.013,0.045$ and $0.065 \%$. The chemical composition of the samples refined with different quantities of titanium is the average of three values obtained by the optical spectrometer shown in Table 2. The experimental matrix is listed in Table 3. 
Table 2: Chemical Composition of the Used Casting Alloy AISi9 (Wt. \%)

\begin{tabular}{|l|c|c|c|c|c|c|c|c|}
\hline \multicolumn{1}{|c|}{ Alloy } & Si & $\mathbf{M g}$ & $\mathbf{F e}$ & $\mathbf{C u}$ & $\mathbf{Z n}$ & $\mathbf{M n}$ & $\mathbf{T i}$ & $\mathbf{A l}$ \\
\hline Untreated sample & 8.626 & 0.022 & 0.398 & 0.064 & 0.41 & 0.173 & 0.013 & bal. \\
\hline Grain-refined sample 1 & 8.652 & 0.015 & 0.406 & 0.058 & 0.414 & 0.168 & 0.045 & bal. \\
\hline Grain-refined sample 2 & 8.716 & 0.013 & 0.416 & 0.056 & 0.411 & 0.173 & 0.065 & bal. \\
\hline
\end{tabular}

Table 3: Experimental Matrix

\begin{tabular}{|c|c|c|c|}
\hline Test & $\begin{array}{c}\text { Titanium } \\
\text { Percentage (Wt. \%) }\end{array}$ & $\begin{array}{c}\text { Initial Mold } \\
\text { Temperature }\left({ }^{\circ} \mathbf{C}\right)\end{array}$ & $\begin{array}{c}\text { Casting } \\
\text { Temperature }\left({ }^{\circ} \mathbf{C}\right)\end{array}$ \\
\hline 1 & 0.013 & 150 & 700 \\
\hline 2 & 0.013 & 150 & 730 \\
\hline 3 & 0.013 & 150 & 765 \\
\hline 4 & 0.013 & 150 & 800 \\
\hline 5 & 0.013 & 300 & 700 \\
\hline 6 & 0.013 & 300 & 730 \\
\hline 7 & 0.013 & 300 & 765 \\
\hline 8 & 0.013 & 300 & 800 \\
\hline 9 & 0.045 & 150 & 700 \\
\hline 10 & 0.045 & 150 & 730 \\
\hline 11 & 0.045 & 150 & 765 \\
\hline 12 & 0.045 & 150 & 800 \\
\hline 13 & 0.045 & 300 & 700 \\
\hline 14 & 0.045 & 300 & 730 \\
\hline 15 & 0.045 & 300 & 765 \\
\hline 16 & 0.045 & 300 & 800 \\
\hline 17 & 0.065 & 150 & 700 \\
\hline 18 & 0.065 & 150 & 730 \\
\hline 19 & 0.065 & 150 & 765 \\
\hline 20 & 0.065 & 150 & 800 \\
\hline 21 & 0.065 & 300 & 700 \\
\hline 22 & 0.065 & 300 & 730 \\
\hline 23 & 0.065 & 300 & 765 \\
\hline 24 & 0.065 & 300 & 800 \\
\hline & & & \\
\hline
\end{tabular}

\section{TATUR Test}

The TATUR test is a technique used to evaluate porosity in aluminum alloys. The TATUR test uses a permanent mold of standard geometry containing two parts, of which, the upper part is conical with an orifice. Figure 1 shows the TATUR specimen.

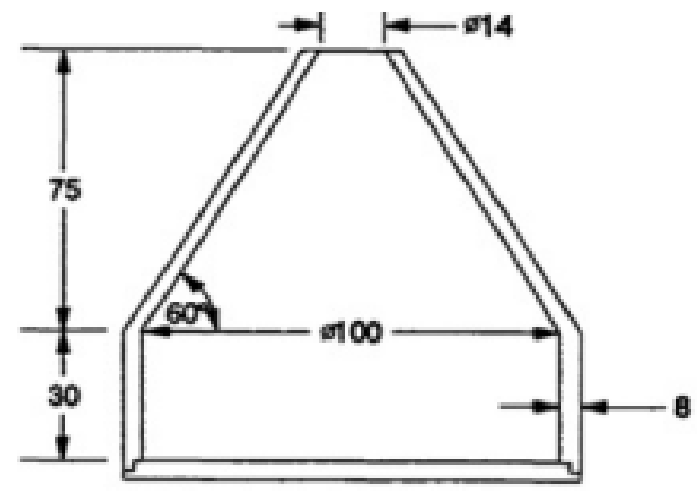

Figure 1: Permanent Mold Used to Cast TATUR Specimen (Mm)[14] 
The present study is based on the use of the TATUR test. The liquid metal is poured through the orifice into the preheated mold. The formation of the shrinkage due to the volume contraction of the metal during solidification is favored by the conical shape of the upper part of the mold. The TATUR test was performed to quantify shrinkage characteristics of the aluminum alloys.

\section{Porosity Measurement}

Porosity is an easy parameter to define, but not easy to quantify. The method used in this study is a nondestructive technique of porosity measurement. The densimetry is an industrial choice that is known for its rapidity of implementation. It will allow direct measurement of all the porosities types (shrinkage porosity, gas porosity). Densimetry is based on Archimedes' principle. Quantitative measure of porosity in the material determined from specific gravity by measuring different weights of the sample in and out of water. The percentage of porosity $\mathrm{g}_{\mathrm{p}}$ of the sample is deduced from an ideal density $\rho_{0}$ (without porosity) with the equation[3]:

$$
g_{p}=\left(\rho_{0}-\rho_{e c h}\right) / \rho_{0}
$$

It is a double weighing of a sample, once in the air $\left(\mathrm{m}_{\text {air }}\right)$ and another time in the water $\left(\mathrm{m}_{\text {water }}\right)$. From these two measurements, the density ratio of the sample to that of the water $\rho_{\mathrm{ech}} / \rho_{\text {water }}$ is obtained.

$$
\rho_{\text {ech }} / \rho_{\text {water }}=m_{\text {air }} /\left(m_{\text {air }}-m_{\text {water }}\right)
$$

The direct measurements of porosity on the test specimens are obtained. In order to draw reliable conclusions, we measure the porosity of ten specimens cast in the same condition.

RESULTS AND DISCUSSIONSFigure 2 shows different forms of internal and external porosities obtained. The areas in contact with the metallic mold do not show any porosity, at least visually. It is found that the shrinkage porosity is concentrated in a middle area around the median line of the cast. Micro and macro-shrinkage are both located in this middle of the specimen. On the other hand, the external shrinkage such macro retassure appears on the free surface and manifests itself in different forms as shrinkage pipe and slump. However, no surface slumping is encountered in the top of the specimens.

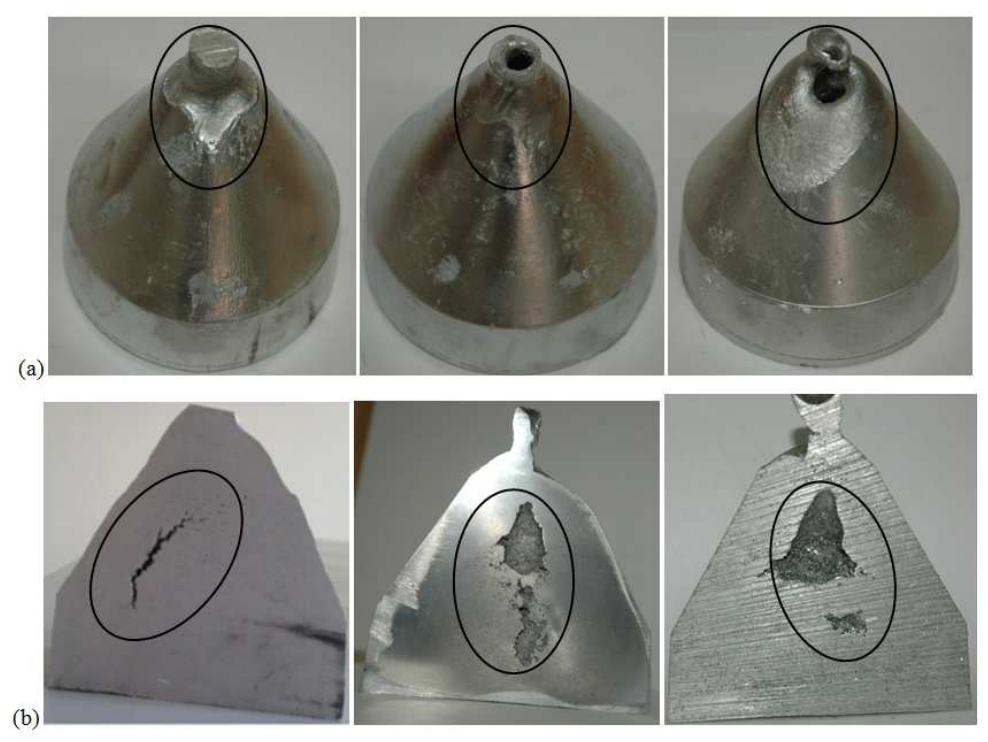

Figure 2: Forms and Positions of (a) External and (b) Internal Porosities 
Near mold's wall, the cooling rate of the metal is high, and therefore the internal regions of the specimen become difficult to feed by liquid metal. Once the solidified metal in mold's wall side comes into contact with that solidified one from the base, the density of the metal decreases. This result was corroborated by numerical study of porosity [15].

Pouring temperature and initial mold temperature are important parameters for casting Al-Si alloys. Figure 3 shows the effect of initial mold temperature and the addition of small amount of grain refiner on porosity in the AlSi9 alloy. It can be seen that high mold temperature decreases porosity values.

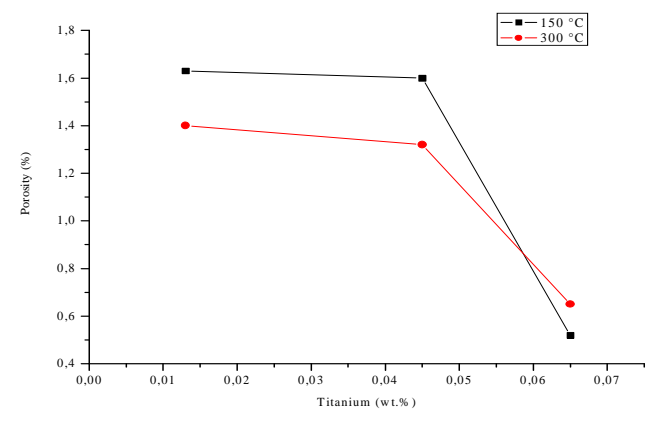

(a)

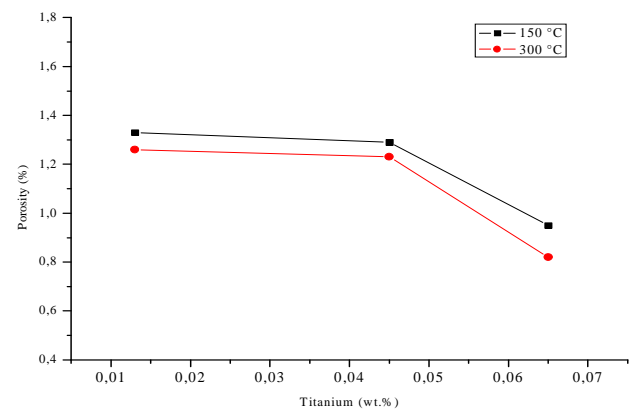

(b)

Figure 3: Effect of Initial Mold Temperature and Titanium Addition on the Porosity in AlSi9 Alloy Cast at: (a) $700^{\circ} \mathrm{C}$,(b) $800^{\circ} \mathrm{C}$

Without any grain refiner addition, it is found that the porosity reaches $1.63 \%$ for the $\mathrm{AlSi} 9$ alloy poured at $700^{\circ} \mathrm{C}$ in a mold preheated at $300^{\circ} \mathrm{C}$. Whereas, when the initial mold temperature is equal to $150^{\circ} \mathrm{C}$, we noted that porosity value is equal to $1.33 \%$. It can be seen obviously that the initial mold temperature influences the solidification time and thus the porosity formation.

Due to the conical shape of the upper part of the mold, the metal which is located at the orifice solidifies first and forms a closed mushy zone which blocks all its supply to liquid metal during solidification. Figure 3(a) shows that the porosity decreases as the titanium addition increases from 0.013 to $0.065 \mathrm{wt}$. \%. With Titanium addition of $0.065 \mathrm{wt}$. $\%$, the percentage of porosity reaches $0.65 \%$ when the initial mold temperature is equal to $300{ }^{\circ} \mathrm{C}$, while the porosity percentage reaches $0.52 \%$ when the initial mold temperature is equal to $150{ }^{\circ} \mathrm{C}$. This decrease is most likely due to the multiplication of germination sites. The grain refiner forms an intermetallic phase that acts as heterogeneous germination sites, which are dispersed into the liquid metal. Titanium added increases the number of germination sites for dendrites and reduces the size of grains, and therefore the pores that appear between the dendrite arms due to the inability of feeding

The pouring temperature is an important parameter, which defines the fluidity of the metal as well as its capacity to fill the interdendritic zones. Figure4 illustrates the combined effect of casting temperature and initial mold temperature on the porosity formation in thealloy AlSi9. It has been found that the pouring temperature has a low effect on the porosity formation. The porosity in the AlSi9 alloy cast in a mold preheated to $150{ }^{\circ} \mathrm{C}$ decreases from $1.63 \%$ to $1.33 \%$, when the pouring temperature of the metal increases from 700 to $800{ }^{\circ} \mathrm{C}$. 


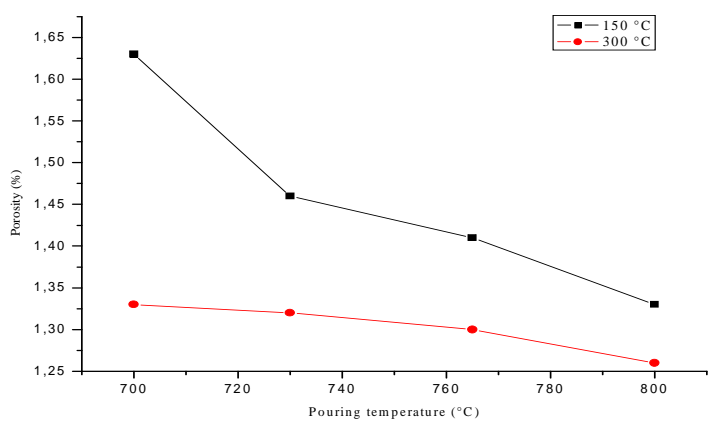

\section{Figure 4: Combined Effect of Casting Temperature and Initial Mold Temperature on Porosity Formation in AlSi9 Alloys}

\section{CONCLUSIONS}

In this work, we quantified the effect of Titanium addition as grain refiner on the AlSi9 cast alloy, and combined effect of process parameters and grain refinement on porosity formation in AlSi9 alloy. The porosity was evaluated using the TATUR test. Densimetry was used as a quantitative method for measuring the porosity value in TATUR specimens. It has been found that the effect of grain refinement by titanium addition on the porosity is more important, when the liquid metal was poured at $700{ }^{\circ} \mathrm{C}$. A small decrease in porosity value was observed with increasing the pouring temperature from 700 to $800{ }^{\circ} \mathrm{C}$. It has been observed that the preheated mold at $300{ }^{\circ} \mathrm{C}$ present small values of porosity.

\section{REFERENCES}

1. Pequet, C., Germaud, M., Rappaz, M. (2002). Modeling of microprosity, macroprosity, and pipe-shrinkage formation during the solidification of alloys using a mushy-zone refinement method: application to aluminiuim alloys. Metallurgical and Materials Transactions A, 33(7), 2095-106

2. Couturier G, Desbiolles J-L, Rappaz M.(2006). A porosity model for multi-gaz systems in multi-component alloys. The Minerals, Metals \& Materials Society

3. Rozot, J. M. (2005). Modèle prédictif de l'apparition de la microporosité de retrait durant la solidification d'un alliage Aluminium-Silicium. Ecole doctorale des sciences physiques et de l'ingénieur, Université de Bordeaux I, France

4. Kaufman, J. G., Rooy, E. L. (2004). The influence and control of porosity and inclusions in aluminum castings. In A. International, ed. Aluminum Alloy Castings: Properties, Processes And Applications. American Foundry Society. Ch. 5, 47-54

5. Dobrzanski, L. A., Maniara, R., Sokolowski, J. H.(2007). The effect of the cooling rate on microstructure and mechanical properties of AC AlSiOCu alloy. Archives of Materials Science and Engineering, 28, 105-112

6. Piatkowski, J., Matuta, T. (2015). The microstructure and mechanical properties of the AlSi17cu5 alloy after heat treatment. Archives of Metallurgy and Materials, 60 (3), 1813-1817

7. Zakaria, K. A., Suhadak, F. H. A., Ali, M. B., Abdullah, S., Ghazali, M. J. (2017). Influence of mechanical properties on load sequence effect and fatigue life of aluminium alloy. Journal of Mechanical Engineering and Sciences, 11(1), 2469-2477

8. Hussain, F., Abdullah, S., Nuawi, M. Z. (2016). Effect of temperature on fatigue life behaviour of aluminium alloy AA6061 using analytical approach. Journal of Mechanical Engineering and Sciences, 10, 2324-35

9. Nafisi, S., Ghomashchi, R. (2006). Grain refining of conventional and semi-solid A356 Al-Si alloy. Journal of Materials Processing Technology, 174(1-3), 371-83. 
10. Anson, J. P.(2000). The Nucléation and. Growth of Microporosiry in Aluminium-7\% Silicium. Foundry Alloy, McGill University, Montreal, Canada.

11. Khudhair, M. R., \& Mallarapu, M. G. K. Frequency Responses Of Aluminum A356 Based On High Strength Alloy Composite (HSAP).

12. Lipiński, T.(2015). Double modification of AlSi9Mg alloy with boron, titanium and strontium. Archives of Metallurgy and Materials,60 (3), 2415-2419

13. Nowak, M., Bolzoni, L., Hari Babu, N. (2015). Grain refinement of Al-Si alloys by Nb-B inoculation. Part I: Concept development and effect on binary alloys. Materials and Design, 66, 366-75

14. Ware, T. N., Dahle, A. K., Charles, S., Couper, M. J. (2002). Effect of Sr, Na, Ca \& P on the Castability of Foundry Alloy A356.2. In 2nd International Aluminium Casting Technology Symposium. Columbus

15. Brůna, M., Sládek, A., Kucharčík, L. (2012). Formation of porosity in Al-Si alloys. Archives of Foundry Engineering, 12(1), 58

16. Ait El Haj, B., Bouayad, A., Alami, M. (2015). A Comparison between Numerical Simulation and Experimental Determination of Porosity. Lecture Notes in Mechanical Engineering. Springer, 789, 297-303. DOI: 10.1007/978-3-319-17527-0_29. 
